\title{
The Use of Consciousness-Raising Tasks in Learning and Teaching of Subject-Verb Agreement
}

\author{
Sirhajwan Idek ${ }^{1}$, Lee Lai Fong ${ }^{1} \&$ Gurnam Kaur Sidhu ${ }^{1}$ \\ ${ }^{1}$ University of Technology Mara, Malaysia \\ Correspondence: Sirhajwan Idek, SMT Keningau, P.O Box 4, 89009, Keningau, Sabah, Malaysia. E-mail: \\ sirhaj87@yahoo.com
}

Received: February 23, 2013 Accepted: April 30, 2013 Online Published: May 8, 2013

doi:10.5539/elt.v6n6p113 URL: http://dx.doi.org/10.5539/elt.v6n6p113

\begin{abstract}
This study investigates the use of two types of Consciousness-Raising (CR) tasks in learning Subject-Verb Agreement (SVA). The sample consisted of 28 Form 2 students who were divided into two groups. Group 1 was assigned with Grammaticality Judgment (GJ) tasks and Group 2 received Sentence Production (SP) tasks for eight weeks. Learners were given a pretest before the treatment and a posttest once they completed the tasks. They were also required to answer questionnaires and some were interviewed. The findings show the two CR tasks promote SVA learning among students but SP tasks are descriptively better than GJ tasks in terms of gain scores.
\end{abstract}

Keywords: Consciousness-Raising (CR) task, Subject-Verb Agreement (SVA), Sentence Production (SP), Grammaticality Judgment (GJ)

\section{Introduction}

\subsection{Subject-Verb Agreement Problems among Malaysians}

Grammar learning has been a persistent challenge to Malaysian students in mastering English. Maros et al. (2007) highlight that secondary school students have difficulties in mastering grammar rules despite the earlier exposure to the language in the primary school for six years. There are many grammar forms that are difficult for our students to learn. Nor Hashimah et al. (2008) identify subject verb agreement, affixes, adverbs, adjectives, plural forms, and copula as the most common mistakes made by students. MohdHilmi and Juliana (2010) discover that students cannot even differentiate simple present tense and past tense whereas Eng and Heng (2005) find that students have poor understanding of relative clauses. Wee (2009) states that Subject-Verb Agreement (SVA) poses the most difficulty for Malaysian students. These findings are corroborated by various studies (SitiHamin et al., 2010; Mahanita et al., 2010; Wee et al., 2010; Surina et al., 2009; Saadiyah et al., 2009; Nor Hashimah et al., 2008) done in Malaysia. In fact, grammar is a major problem area faced by students in writing (Mahanita et al., 2010).

Bautista and Gonzales (2006) state that the English spoken by Malaysians contains frequent types of error which are misinformation and omission. It results in "phrasal telegraphic speech", a toddler's speech rather than complete utterances. Some evident examples among Malaysians are "She sick", "Can", "It missing", etc. Subject and verbs are the two important elements in producing complete and correct sentence (SitiHamin et al. 2010; Surina\&Kamaruzaman, 2009). They provide the very fundamental aspect of language production. This is why grammar particularly SVA needs to be emphasized in language learning.It is important for the purpose of communication (Long et al., 1980; Savignon, 1991). In addition, SVA has been listed as a compulsory grammatical component to be taught in all forms in secondary school. It is stated in the syllabus for the Integrated Secondary School Curriculum for English language outlined by the Curriculum Development Center (Ministry of Education, 2000).

The Deputy Prime Minister of Malaysia and Minister of Education, Tan Sri MuhyiddinYassin has asserted the importance of bringing back grammar teaching to the classroom. He states its significance as follow:

"Language learning should begin by making students excited and interested. Language is dynamic. It is alive and kicking. Great stories are told in beautifully crafted words. Wordsmiths are the geniuses of civilization. They make us love the language. We admire their works for that. To achieve that, they have to write well. Even if we 
can't be like them at least we can use language to communicate effectively or at least write simple sentences to express our thoughts and views. It all begins with grammar" (Johan, 2012, p. A5).

Ting (2007) states that 96 percent of teachers teaching English in Malaysian schools perceive that grammar should be taught to learners. In spite of the support for grammar teaching, our students are continuously struggling to master grammar. In line with this, Wee (2009) claims that lack of grammar emphasis in teaching is the main reason why students cannot master grammar rules. However, some link this to grammar teaching. There are many techniques of teaching grammar in Malaysian classrooms that have been criticized for being ineffective. Chung (2004) criticizes drilling exercises and teacher-fronted explanation practiced during English grammar lessons. Ming and Nooreiny (2010) disapprove of the mechanic deductive method of grammar adopted by many teachers. Ambigapathy (2002) points out that teachers teach too many grammatical skills to students through constant drilling on past year examination questions, worksheets and exercise books. Besides, Hawanum (2004) claims that Malaysian teachers are not clear on how deep they should explore grammar in explaining it to learners.

In searching for an effective method to teach grammar, it is important to look into whether the method is applicable or not in the Malaysian classroom. Nassaji and Fotos (2004) cite that one of the popular ways of teaching grammar in the language classroom is Consciousness-Raising (CR), a method used in task-based approach. Ellis (2002, p. 169) describes that the purpose of CR is "not to enable learners to perform a structure correctly but simply to help him/her to know about it". It is fully defined as "a pedagogic activity where the learners are provided with L2 data in some forms and required to perform some operation on or with it, the purpose of which is to arrive at an explicit understanding of some linguistic property or properties of the target language" (Ellis, 2003, p. 160). CR focuses more on developing correct understanding than correct production of target form (Ellis, 2003) and this possibly can address learners' major weakness in their knowledge of grammar especially SVA.

\subsection{Awareness of Subject-Verb Agreement}

This study is important to determine whether CR can increase learners' awareness of SVA. Ellis (2003) hypothesizes that CR draws learners' attention towards the target form without involving drilling towards correct production. The purpose is to develop awareness of the target form which according to Rachmawati (2011) is important to prepare learners for the next stage where they are ready to insert this specific feature into their interlanguage, thus, acquiring it permanently. Until they gain enough awareness of SVA, they will not be able to produce comprehensible sentences especially when subjects and verbs are the significant element of a language production (SitiHamin et al., 2010; Surina \& Kamaruzaman, 2009). Schmidt (1990) claims that learners will not learn anything if their learning is not preceded by attention and awareness.

The study is also important for teachers who constantly face difficulties in teaching this form to students. Teachers are facing the issue of how they actually should be teaching grammar in English lessons (Vethamani\&Umi Kalthom, 2008; Hawanum, 2004). Hawanum (2004) further claims that Malaysian ESL teachers, being L2 speakers themselves, are often not certain on how to teach grammar to their students especially in exploring the details of grammar they need to explain to learners. This study can pave the way for teachers to teach students SVA through CR tasks and it can be an effective technique that teachers can adopt and apply in their classes.

\subsection{Relevant Literature}

Maros et al. (2007) carried out a research on 120 students from six rural schools in Pahang, Selangor and Melaka. The findings show that one of the major grammatical errors that students make is SVA. Meanwhile, Nor Hashimah et al. (2008) conducted a study on 315 students in Form Two and it is discovered that some Malaysian students are unable to produce correct sentences due to their lack of competence in SVA.

Malaysian students' lack of awareness on the forms and functions of SVA is evident. They are able to arrange words accordingly; subject-verb-object or subject-predicate (Abdul Rashid Mohamed et al., 2004) but they are not able to progress into mastering SVA. They are not well aware of the characteristics of SVA, a grammar structure that is absent in their first language (Wee, 2009). Their lack of awareness about it might be the reason why interference from their first language occurs and hinders them from learning it (Surina and Kamaruzaman, 2009). In fact, they develop confusion when applying SVA (Shazwani, 2008; Surina and Kamaruzaman, 2009). Their inability to understand or use SVA will persist if they do not gain sufficient knowledge about it.

Radha, Noraini and Krish's (2008) research on language learning strategies adopted by Form Two students in Johor reveal that learners tend to use strategies that do not require them to be analytical and critical, hence, 
hindering them from fully grasping the concept of grammatical rules. Normazidah et al. (2012) claim that learners should be more cognitively involved in discovering the rules in order to overcome any possible misinterpretation. Therefore, it is recommended in their study that grammar teaching requires teachers to employ teaching methods that encourage learners to be more sensitive to the structure and make them aware of the correct use through the use of explanation and self-discovery. Learners need sufficient input and instruction from teachers and they have to be given activities that can cognitively push them to discover the rules on their own. In addition, the target form has to be given more physical and cognitive prominence in any task (Normazidah et al., 2012).

In identifying the teaching method that can cater to learners' needs, the characteristics of CR should be further explored. CR emphasizes explicit explanation from teacher (Ellis, 1992, 2003, 2006; Fotos and Elis, 1999), prioritizes learners' self-discovery of the rules (Ellis, 1992, 2003, 2006) and presents target form in an attention drawing manner (Ellis, 1992, 2003, 2006; Schmidt, 1990). Above all, it promotes learners' awareness of the target form, which according to Schmidt (1990) is the earlier and essential stage of learning. Schmidt (1990) believes that before learners can learn anything, they have to be aware first of what they are learning, pay attention to it and notice it. It is possible that Malaysian students are not aware of the forms they are being taught and their lack of awareness hinders them from making progress and subsequently, mastering the language. Ellis (2003) advocates that CR is able to promote learners' awareness of the target form which will gradually lead them into correct production. In view of these, CR appears to be a plausible approach in promoting grammar learning.

Fotos and Ellis (1991) discover that CR positively increases learners' understanding of dative alternation (prepositional indirect object construction). They administered interactive grammar tasks to Japanese EFL college students: students of Language majors and Business Administration majors. They were assigned into three groups: a control group that received face-to-face instruction from the teacher followed by a reading assignment, an experimental group that performed information gap tasks in pairs and another experimental group that performed the tasks in several groups of four members. The findings reveal that the more members in a group, the better they perform in the post test. Fotos (1994) also conducted another research on CR among 169 Japanese students whom she assigned into three groups. One group received interactive, grammar problem-solving task, one group received teacher-fronted grammar lesson and the control group was assigned with reading assignments only. The target forms were dative alternation, adverb placement and relative clause. Both experimental groups' posttest scores increased significantly after the treatments.

A previous research on the use of CR in teaching grammar on Malaysian learners was conducted by Ming and Nooreiny (2010). 36 students of Diploma in Business Administration were given CR activities with personal pronouns ("I" and "we") as the target form. The results from post test scores indicate that the learners' knowledge of the target form increased after the treatment. The findings from the questionnaires administered to the learners imply that the $\mathrm{CR}$ activities facilitate the learners to explore and recognize the target form. These studies were conducted on adult learners of higher education. This study is aimed towards Malaysian school students and it addresses SVA, an error frequently committed by Malaysian learners. Hence, the investigation on the use of CR in teaching grammar is crucial in order to identify the effects of the CR tasks on secondary school students, the type of CR tasks that suit the students' abilities and the effects of CR on SVA, the major error committed by school students. This study focuses on school context with SVA as the target form.

\subsection{Objectives and Research Questions}

The objective of this study is to examine the effects of two CR tasks: sentence production and grammatical judgment in helping learners to learn SVA. It also aims to investigate the learners' perceptions of the benefits of the tasks in learning SVA. The research questions are:

1. Which CR task: sentence production (SP) or grammatical judgment (GJ) is more effective in helping students to learn SVA?

2. What are learners' perceptions on the benefits of CR tasks in learning SVA?

3. What are the characteristics of CR that promote SVA learning?

\section{Methods}

\subsection{Subjects}

The subjects were from an intact Form 2 ESL classroom of 28 students in a secondary school located in Ranaudistrict, a rural area in Sabah. There was only one class for Form Two in the school. Their English proficiency was intermediate as indicated by their mid-term exam scores. The subjects were randomly assigned 
into two groups, Group 1, which was given Sentence Production (SP) tasks and Group 2 which was assigned with Grammaticality Judgment (GJ) tasks.

\subsection{Data Collection}

The research was conducted for 11 weeks which consisted of one week for pre-test, eight weeks of treatment, one week for post-test and one week for questionnaire survey and interview. There were three sub-rules of SVA addressed in the treatment: verbs "be", "have", and "do".

A similar test which consisted of 20 questions on SVA was used for the pretest and the posttest. The learners were given 30 minutes to complete both tests. In implementing the CR tasks, a lesson based on PPP (Presentation, Practice \& Production) model was developed. During the presentation stage, the teacher provided explicit explanations of the rules to the subjects. The presentations were followed by practices where the learners had to underline sentences with the target form in a given passage and provide explanations on its usage in the sentences. The CR tasks were administered in the production stage. There were two types of tasks: sentence production (SP) and grammaticality judgment (GJ). Group 1 was given SP tasks and Group 2 received GJ tasks and they were given 15 minutes to complete the tasks.

Group 1 was given a set of 12 pictures with some prompt words for each picture. The objective of the task was for the learners to be able to produce 12 sentences with the correct use of the target form, one sentence for each of the given pictures. Group 2 was given 12 sentences and the objective was for the learners to identify whether the use of the target form in each of the sentences was wrong or correct.

In week 11, each learner was given a questionnaire. It comprised three dimensions and covered 11 items. Three items were allotted to cognitive domain of development (Bloom, 1956 as cited in Santrock, 2008), six items on operational skills (Willis and Willis, 2007), and two items about task factors (Ellis, 2003). Bloom's cognitive domain of development was narrowed into the first three categories: "remember", "understand" and "apply". Likert-scale that comprised five scales (strongly agree, agree, neutral, disagree, strongly disagree) was used to obtain students' responses. Ten minutes were allocated to students to complete the questionnaire.

After the treatment, five students were randomly selected from each group for the interview. The interview was semi-structured and consisted of six questions. The questions investigated the learners' perception of the difficulty of the tasks, the usefulness of the tasks and the characteristics of the tasks. Each respondent was interviewed for 10 minutes in which the researcher took note of the verbal responses of the students.

\subsection{Data Analysis}

Both the pretest and the posttest contained 20 items and one score was allocated to one item. Hence, there was a total score of 20 for each test. Paired sample t-test was used to compare the means of pretest and posttest scores in both groups in order to determine the difference between the two and its statistical significance. The data from the questionnaire was tallied and their means were obtained. The responses from the interview were analyzed and coded based on themes that emerged.

\section{Results}

\subsection{Students' Performance in CR Tasks}

A dependent sample t-test was used to identify the significance of difference between pretest scores and posttest scores within Group 1(SP) and Group 2 (GJ) respectively.

Table 1. The results of dependent sample t-test within Group 1 and Group 2

\begin{tabular}{|c|c|c|c|c|c|c|}
\hline & Pre-test & Post-test & $\begin{array}{l}\text { Mean } \\
\text { difference }\end{array}$ & $\mathrm{t}$ & $\mathrm{df}$ & $\begin{array}{l}\text { Sig. } \\
\text { (2-tailed) }\end{array}$ \\
\hline $\begin{array}{l}\text { Group } \\
1 \text { (SP) }\end{array}$ & 9.93 & 13.43 & 3.05 & 3.79 & 13 & $(.002)$ \\
\hline $\begin{array}{l}\text { Group } \\
\text { 2(GJ) }\end{array}$ & 8.71 & 10.86 & 2.15 & 2.23 & 13 & $(.044)$ \\
\hline
\end{tabular}

* The mean difference is significant at the 0.05 level

Table 1 reveals that $\mathrm{p}$ value of Group 1 (SP) is less than 0.05 . Hence, the mean difference is statistically significant. The $\mathrm{p}$ value of Group 2 (GJ) is also less than 0.05 , indicating that the mean difference is also significant. Based on the findings, there are increases in scores of both groups in posttest and the difference of pretest and posttest scores of Group 1 (SP) and Group 2 (GJ) are statistically significant. 
Next, learning gain scores from each individual performance in pretest and posttest was obtained and the means of these gain scores were calculated separately based on groups. An independent t-test was performed on the two means of the learning gain scores obtained from Group 1 (SP) and Group 2 (GJ) respectively.

Table 2. The results of independent sample t-test between Group 1 and Group 2

\begin{tabular}{llllll}
\hline & Mean & $\begin{array}{l}\text { Std. } \\
\text { Deviation }\end{array}$ & $\mathrm{T}$ & $\mathrm{df}$ & $\begin{array}{l}\text { Sig. } \\
(2 \text {-tailed) }\end{array}$ \\
\hline Group 1(SP) & .25 & .26 & .67 & 26 & $(.51)$ \\
Group 2(GJ) & .18 & .27 & & & \\
\hline
\end{tabular}

* The mean difference is significant at the 0.05 level

The $\mathrm{p}$ value is not less than 0.05 . Statistically, there is no significant difference between learning gain scores between Group 1 (SP) and Group 2 (GJ). Descriptively, SP tasks are more effective in increasing learners' knowledge of SVA as implied by higher average learning gain score of the learners in Group 1(SP) than Group 2 (GJ).

\subsection{Learners' Perceptions on Benefits of CR Tasks in SVA Learning}

With regard to the second research question on learners perceptions on benefits of both CR tasks in learning SVA, the responses from the questionnaires were divided into three sections: cognitive domains of learning (Bloom, 1956 as cited in Santrock, 2008), operational skills (Willis and Willis, 2007) and task factors. The responses were tallied in accordance with the Likert-scale and converted to means.

Table 3. Learners' perception on the benefits of the tasks on Bloom's Taxonomy's cognitive domain of learning

\begin{tabular}{lllll}
\hline & Group 1 (SP) & & Group 2 (GJ) & \\
\hline Cognitive & Mean & Std. Deviation & Mean & $\begin{array}{l}\text { Std. } \\
\text { Deviation }\end{array}$ \\
Domains & & & & .95 \\
Knowledge & 3.71 & .73 & 3.14 & .83 \\
Understanding & 3.93 & .73 & 3.93 & .84 \\
Application & 3.15 & .80 & 3.64 & \\
\hline
\end{tabular}

The results in Table .3 indicate that learners in Group 1 (SP) and Group 2 (GJ) generally had moderate perceptions on the level of knowledge, understanding and even application of the target form they had gained from the tasks. Learners in Group 1 (SP) had better perception on the benefit of the SP tasks in increasing their knowledge (mean=3.71, SD=.73) than Group 2 (GJ) (mean=3.14, SD=.95). In terms of increasing their application of SVA, Group 2 (GJ) had better perception (mean=3.64, SD=.84) than Group 1 (SP) (mean=3.15, $\mathrm{SD}=.80$ ). Both groups had nearly similar level of responses on the benefits of the respective tasks in increasing their understanding of the target form, Group 1 (SP) with (mean=3.93, SD=.73) and Group 2 (GJ) with (mean=3.93, $\mathrm{SD}=.83$ ).

Table 4. Learners' perception on the benefits of the tasks on operational skills

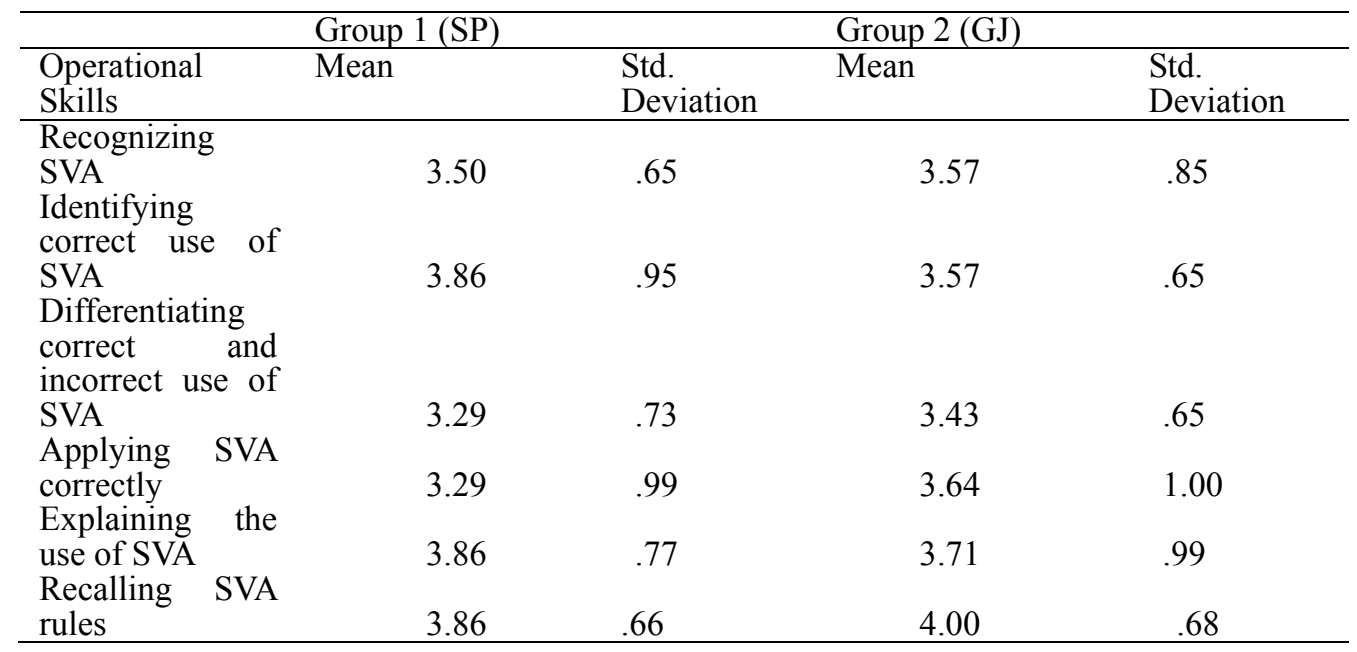


The findings in Table 4 indicate that learners had moderate responses towards the effects of CR tasks in increasing their operational skills. Students in Group 2 (GJ) (mean=3.57, $\mathrm{SD}=.85$ ) had slightly better perception of their improved ability to recognize SVA than students in Group 1 (SP) (mean=3.50, SD=.65). Nevertheless, the students in Group 1 (SP) had better perception of their improved ability to identify correct use of SVA (mean= 3.86, $\mathrm{SD}=0.95$ ) than students in Group 2 (GJ) (mean=3.57, SD=0.65). Students in Group 2 (GJ) had better perception of their improved ability to differentiate correct and incorrect use of SVA (mean $=3.42$, $\mathrm{SD}=0.65$ ) than Group 1 (GJ) (mean=3.29, $\mathrm{SD}=0.73$ ). Group 2 (GJ) also had better perception of towards their improved ability to produce sentences with the correct use of SVA (mean=3.64, SD=1.00) than Group 1 (SP) (mean=3.29, $\mathrm{SD}=.99$ ). In terms of their improved ability to recall SVA rules, Group 2 (GJ) had better perception $($ mean $=4.00, \mathrm{SD}=.68)$ than Group $1(\mathrm{SP})($ mean $=3.86, \mathrm{SD}=.66)$.

Table 5. Learners' perception of CR tasks on motivation and effectiveness of tasks

\begin{tabular}{lcccc}
\hline & Group 1 (SP) & & Group 2 (GJ) & \\
\hline Task Factors & Mean & Std. Deviation & Mean & Std. Deviation \\
Motivation & 3.86 & 1.03 & 4.21 & .70 \\
Effectiveness & 3.86 & .86 & 3.93 & 1.07 \\
\hline
\end{tabular}

The findings in Table 5 reveal that students in Group 2 (GJ) had better perception of the motivation of the tasks in encouraging learners to learn SVA (mean=4.21, $\mathrm{SD}=.70$ ) than students in Group 1 (SP) (mean=3.86, $\mathrm{SD}=1.03$ ). Group 2 (GJ) also had better perception of the effectiveness of the tasks in promoting learning SVA (mean=3.93, $\mathrm{SD}=1.07)$ than Group $1(\mathrm{SP})$ (mean=3.86, $\mathrm{SD}=.86$ ).

\subsection{Characteristics of $C R$}

The data from their interview were categorized based on emerging themes. There are three main features of CR that the learners claimed to have helped them understand SVA: operational skills, collaboration with peers and explicit instruction. This addresses the third research question on the characteristics of CR that promotes SVA learning.

Most of the responses indicate that the tasks are useful in grammar learning because the tasks require the learners to perform certain operational skills in solving the problems. Three respondents stated that SP tasks helped them to learn to use singular form and plural form: "I learn how to use singular (is, was) and plural (are, were) in sentences," "I learn it through practice of making sentence, reading and understanding the passage" and "I learn it by doing some sentences". Two respondents claimed that GJ task demanded them to identify the meanings of the words: "I try to understand the meaning of the sentences" and "I look the meaning of the word in the dictionary". One respondent attributed the learning to identification skill that "Every CR tasks given to use, we must find what the questions want and we need to refer to the text given". These imply that the requirement for operational skills to perform the tasks contributes to their successful learning of SVA. Based on the data from the questionnaires, the students also have moderate responses on operational skills in CR tasks as indicated by the means attained in each of the skill.

In addition, the majority of the responses imply that collaboration with peers help learners to learn the target form because it encourages them to discuss with their partners to solve the tasks. One respondent said, "Yes, discussion with friends can help me to understand more about SVA" and another respondent said, "Yes, because we can share our knowledge". The explicit instructions given before the tasks are also useful in promoting the learners' awareness of the target forms in CR method. Four respondents claimed that the examples presented by their teacher helped them in their understanding and five respondents attributed their understanding to the emphasized, slowly-paced and comprehensive manner of their teacher's explanation. One respondent stated, "The teacher slowly explained everything and tried to make us understanding" and another respondent said, "She wanted us to know and understanding about subject-verb agreement and how to use it".

\section{Discussion}

\subsection{Sentence Production and Grammaticality Judgment}

The results of the dependent sample t-test within Group 1 (SP) and Group 2 (GJ) indicate that there are increases in the posttest scores. However, there is no significant difference between the means of learning gain scores between the two groups. The results of the t-test indicate that the mean differences of pretest and posttest scores within Group 1(SP) and within Group 2 (GJ) are significant. Descriptively, the mean difference of pretest and 
posttest scores and the mean of learning gain scores obtained by Group 1 imply that SP tasks are better in increasing students' accuracy in understanding and applying SVA. This addresses the first research question of which of the two types of CR tasks that is more effective in promoting SVA learning.

Students in Group 1 (SP) who performed SP tasks did better in the post-test than Group 2 (GJ) because sentence production is considered as a production task whereas grammaticality judgment is a comprehension task. Jong (2005) claims that production task requires more cognitive demands than comprehension task. SP tasks require the subjects to invest more effort and perform numerous skills of generating ideas, selecting vocabularies, structuring sentences and deciding on the correct use of the verb "be". The high demand of this task "forces" learners to notice the target form in order to complete the task (Skehan, 1998; Schmidt, 1990). Hence, learners in Group 1 (SP) managed to obtain more knowledge of SVA than Group 2 (GJ) because they had performed SP tasks.

\subsection{Students' Perception of the Benefits of CR Tasks}

The results in Table 3 indicate that learners of Group 1 (SP) and Group 2 (GJ) generally had moderate perceptions on the level of knowledge, understanding and even application of the target form they had gained from the tasks. Sugiharto (2006) claims that CR is not meant to produce students with immediate grammatical proficiency as CR serves as a means, not an end in itself. This explains why learners only had moderate responses on their knowledge, understanding and application of SVA because they were not expected to master the form within an instant and short period of time.

The students in Group 1 (SP) had better responses on their improved ability to identify correct use of SVA than students in Group 2 (GJ). This can be attributed to the design of SP tasks that Group 1 (SP) was assigned with during the study. SP tasks are considered as production tasks that have higher demand than comprehension tasks (Jong, 2005) which leads them to pay more attention to the target form (Schmidt, 1990). Hence, learners in Group 1 (SP) were more aware of the correct form of SVA due to the level of attention they had devoted to that particular feature. Students in Group 2 (GJ) had better responses towards their improved ability to differentiate correct and incorrect use of SVA (mean $=3.42, \mathrm{SD}=0.65)$ than Group 1 (GJ) (mean=3.29, SD=0.73). Learners in Group 2 (GJ) performed GJ tasks which required them to identify whether the use of the target form was wrong or correct in a set of sentences for every task. Hence, the skill required in completing the tasks directly improved their skill in differentiating the correct and incorrect use of SVA as implied by their responses.

Surprisingly, Group 2 (GJ) had better responses towards their improved ability to produce sentences with the correct use of SVA than Group 1 (SP) although it was Group 1 (SP) that performed SP tasks. The learners in Group 1 (SP) were clearly instructed to write sentences which contained correct target form whereas Group 2 (GJ) only had to identify the wrong and correct use of SVA. Group 1 (SP) had lower mean of responses on this skill. This can be due to the higher demand of a production task which pushes learners to notice their knowledge deficiency in using the target form correctly (Jong, 2005; Schmidt and Frota, 1986). Hence, learners in Group 1 (SP) were better aware of their actual competence in using SVA than learners in Group 2 (GJ).

The findings in Table 5 imply that the students had moderate perceptions towards motivation and effectiveness of CR tasks in promoting SVA learning.

In addressing the second research question on learners' perceptions on the benefits of CR tasks, learners in both groups indicated moderate perceptions on the effect of tasks in increasing their knowledge, understanding and application of target form. In terms of operational skills they gained from the CR tasks, they generally had moderate perceptions towards all the skills. Likewise, they also indicated moderate responses in their perception of CR in terms of motivation and effectiveness in promoting SVA learning.

\subsection{Characteristics of CR Tasks that Promote SVA Learning}

\subsubsection{Operational Skills}

Ellis $(2003,2006)$ claims that CR requires learners to use intellectual effort and perform operational skills to understand a target form. In fact, Schmidt (1990) claims that such task design can help learners to pay more attention to the forms. The more learners have to invest their intellectual effort, the higher their chance is to be able to understand and remember the rules (Thornbury, 2009). These are supported by one respondent who explicitly claimed that "the tasks want to test our understanding about SVA" and another respondent said that the tasks caused him or her to pay more attention because he claimed that "If I did not pay attention, I couldn't understand it".

The two tasks demand some operational skills in order to be completed. SP tasks require the skill of producing sentences with the correct target form and GJ tasks require learners to identify the correct use of forms. 
Participant 1 claimed that "Such exercises helped to consolidate my knowledge and it helped me to know about it, before this, I didn't know about it". It indicates that doing the tasks which require certain operations help students to improve their understanding of the rules which they are not aware or familiar before. Learners were also asked about their responses towards the practice of providing explanations on the use of the target form in the sentences that they had underlined in a text. Such requirement is one of the distinct features of CR as Ellis (2003) claims that learners need to articulate the rules describing grammatical features. The respondents' responses towards the practice are positive. Most of them claimed that their understanding of the rules became much clearer when they had to provide explanations on how the rules worked. A respondent claimed that "it is easier to understand the rules when you had to give explanation to them on your own". This implies that the skill of describing rules is just as effective as the operational skills required in the two main tasks: sentence production and grammaticality judgment.

\subsubsection{Collaboration with Peers}

In CR, the tasks need to be implemented through a communicative nature (Ellis, 2003; Widodo, 2006). The opportunity for students to communicate with a partner in the task allows them to share their knowledge and help each other to further develop their understanding. In the previous research conducted by Ellis and Fotos (1991), Fotos (1994), Ming and Nooreiny (2010) indicate that interactive and collaborative nature of CR tasks enhanced the subjects' grammatical knowledge.

\subsubsection{Explicit Instruction}

Unlike other approaches where the role of explicit instruction is downplayed (Skehan, 1998), the explicit explanation from the teacher is an integral part of CR and learners were positive about the instruction given by the teacher. Schmidt (1990) describes the instruction as instrumental in bringing the learners' attention to the target form in a way that establishes their expectation. Ellis (2003) highly emphasizes the use of explicit instruction in the implementation of CR in grammar learning.

In conclusion, SP tasks are better in promoting SVA learning than GJ tasks. This is due to the higher "task demand" of productive tasks (SP) than comprehension tasks (GJ). This can be attributed to the nature of SP tasks as production tasks that push learners to invest more cognitive effort in completing the tasks (Swain, 1985) that results in their increased attention of the target form (Schmidt, 1990).

Learners generally had moderate perceptions on the effects of the tasks in improving their knowledge, understanding and application on SVA, operational skills they gained from the two CR tasks, as well as the motivation and effectiveness of the tasks. They all responded positively that the tasks are effective and motivating ways of learning SVA. On the whole, CR tasks help to promote the learners' grammar learning of SVA through the demand for operational skills, and through explicit instruction and collaboration with peers. Explicit instructions help learners to receive sufficient input on how the grammatical rules work. Meanwhile, performing operation on the tasks enhances learners' awareness of the target form and its usage (Schmidt, 1990) and helps them to retain longer memory of their knowledge (Ellis, 2003; Thornbury, 2009) and collaboration with peers allow them to share knowledge. This eventually helps them to learn the target form as they manage to invest more attention on the form and started to become aware of it (Schmidt, 1990). To an extent, CR tasks can be implemented in grammar teaching in order to promote learners' learning of important grammatical rules and help to overcome the problem of lack of language proficiency among our students.

\section{Acknowledgements}

Dr. Teoh Seon Hoon.

\section{References}

Abdul Rashid Mohamed, Goh Li Lian, \& Wan Rose Eliza. (2004). English errors and Chinese learners. Sunway College Journal, 1, 83-97.

Ambigapathy, P. (2002). English language teaching in Malaysia today. Asia Pacific Journal of Education, 22(2), 35-52. $\quad$ Retrieved $30 \quad$ January, $2011, \quad$ from http://www.tandfonline.com/doi/abs/10.1080/0218879020220205\#preview

Bautista, M. L. S., \& Gonzales, A. B. (2006). Southeast Asian Englishes. In B. B. Kachru, Y. Kachru, \& C. L. Nelson (Eds.), The handbook of World Englishes (pp. 130-144). Malden, MA: Blackwell.

Chung, S. F. (2004). Communicative approach to teaching Grammar: Theory and Practice. The English Teacher, 34, 33-50.

Ellis, R. (2006). Current Issues in the Teaching of Grammar: An SLA Perspective. TESOL Quarterly, 40(1), 


\section{3-107. http://dx.doi.org/10.2307/40264512}

Ellis, R. (2003). Task-based language learning and teaching. Oxford. Oxford University Linguistics.

Ellis, R. (1992). Second language acquisition and pedagogy. Clevedon.Multilingual Matters.

Ellis, R. (2002). Frequency effects in language processing: A review with implications for theories of implicit and explicit language acquisition. Studies in Second Language Acquisition, 24, 143-188.

Eng, W. B., \& Heng, C. S. (2005). English relative clause: what Malay learners know and use. Pertanika Journal of Social Science and Human, 13(1), 107-115.

Fotos, S., \& Ellis, R. (1999). Communicating about grammar. Learning a Second Language Through Interaction, 8, 189-208. http://dx.doi.org/10.2307/3587079

Hawanum Hussein. (2004). Using simple poems to teach grammar. The Internet TESL Journal, 10(5), 12-24.

Johan Jaaffar. (2012, October 06). Teaching English, and grammar; the old way. New Straits Times, p. A5.

Jong, N. D. (2005). Can second language grammar be learned through listening? An Experimental Study. Studies in second language acquisition, 27, 205-234.

Long, M. H., Allen, W., Cyr, A., Lemelin, C., Ricard, E., Spada, N., \& Vogel, P. (1980). Reading English for academic study. New York: Newbury House.

MahanitaMahadhir, Ting, S. H., \& Chang, S. L. (2010). Grammatical errors in a spoken English of university students in oral communication course. GEMA online Journal of Language Studies, 10(1), 53-70.

Malaysian Ministry of Education. (2000). Integrated Secondary School Curriculum for English language. Kuala Lumpur: Ministry of Education.

Maros, M., Tan Kim Hua, \& KhazriyatiSalehuddin. (2007). Interference in learning English: Grammatical errors in English essay writing among rural Malay secondary school students in Malaysia. Jurnal e-Bangi, 2(2), $1-15$.

Ming, C. S., \& NooreinyMaarof. (2010). The effect of C-R activities on personal pronoun acquisition. Procedia Social and Behavioral Sciences, 2, 5045-5050.

Mohd.Hilmi, H., \& Juliana Emilia, D. (2010). Using grammar games in teaching grammar: A case study in SMK Damai Jaya. Unpublished Manuscript.

Nassaji, H., \& Fotos, S. (2004). Current developments in research on the teaching of grammar. Annual Review of Applied Linguistics, 24, 126-145.

Nor Hashimah, J. Norsimah, M. A., \& Kesumawati, A. B. (2008). The mastery of English language among lower secondary school students in Malaysia: A linguistic analysis. European Journal of Social Sciences, 7(2), 106-119.

NormazidahChe Musa, Lie, K. Y., \& Hazita Azman. (2012). Exploring English language learning and teaching in Malaysia. Journal of Language studies, 12(1), 35-51.

Rachmawati, R. (2011). Consciousness-raising (CR): An alternative approach to teaching grammar. Jurnal Penelitian Dan Pemikiran Pendidikan, 1(1), 82-90.

Radha, N. Noraini, \& $\quad$ Krish, $\quad$ P. PenggunaanstrategipembelajaranbahasadalamkalanganpelajarTingkatanDua. Journal e-Bangi, 3(3), 1-17.

SaadiyahDarus, \& Ching, K. H. (2009). Common Errors in Written English Essay of Form One Chinese Students: A Case Study. European Journal of Social Science, 10(2), 242-253.

Santrock, J. W. (2008). Educational Psychology (3rd ed.). New York: McGraw-Hill Education.

Savignon, S. J. (1991). Communicative language teaching: state of the art. TESOL Quarterly, 25(2), 261-277. http://dx.doi.org/10.2307/3587463

Schmidt, R. (1990). The role of consciousness in second language learning. Applied Linguistics, 11, 129-158.

Schmidt, R., \& Frota, S. (1986). Developing basic conversational ability in a second language.A case study of an adult learner of Portuguese. In R. Day (Ed.), Talking to learn: Conversation in second language acquisition pp. 237-326.). Rowley, MA: Newbury House.

Shazwani Abd Rahman. (2008). Using songs to reinforce the learning of subject-verb agreement. Unpublished Manuscript. 
SitiHamin, \& Mohd Mustafa. (2010). Analysis of errors in subject-verb agreement among Malaysian ESL learners. The Southeast Asian Journal of English Language Studies, 16(1), 56-73.

Skehan, P. (1998). A cognitive approach to language learning. Oxford: Oxford University Press.

Sugiharto, S. (2006). Grammar consciousness-raising: research, theory and application. Indonesian Journal of English Language Teaching, 2(2), 140-148.

SurinaNayan, \& KamaruzamanJusoff. (2009). A study of subject-verb agreement: From novice writers to expert writers. International Education Studies, 2(3), 190-194.

Swain, M. (1985). Communicative competence: Some roles of comprehensible input and comprehensible output in its development. In Gass, S., \& Madden, C. (Eds.), Input in second language acquisition (pp. 235-256). Rowley, MA: Newbury House.

Thornbury, S. (2009). How to teach grammar. Malaysia: Longman.

Ting, S. H. (2007). Is teacher education making an impact on TESL teacher trainees' beliefs and practices in grammar teaching? English Language Teacher Education and Development, 10, 42-62.

Vethamani, M. E., \& UmiKalthom, A. M. C. (2008). Students use of modals in narrated composition forms and functions. English Language Teaching, 1(1), 61-74.

Wee, R. (2009). Source of errors: an interplay of interlingual influence and intralingualfactors. European Journal of Social Science, 11(2), 349-359.

Wee, R. Sim, J., \& Kamaruzaman Jusoff. (2010). Verb-form errors in EAP writing. Educational Research and Review, 5(1), 16-23.

Widodo, H. P. (2006). Approaches and procedures for teaching grammar. English Teaching: Practice and Critique, 5(1), 122-141.

Willis, D., \& Willis, J. (2007). Doing task-based teaching. Oxford. Oxford University Press. 